\title{
Construção de conceitos no campo da ciência da informação*
}

\section{Maria Cristiane Barbosa Galvão}

\section{Resumo}

A construção de conceitos interfere na ruptura epistemológica de uma ciência com o senso comum e no desenvolvimento de modelos científicos voltados para a observação, descrição e interpretação dos objetos teóricos e empíricos de um campo do conhecimento. A formação do arcabouço conceitual da biblioteconomia e documentação parece ter tido por base o fluxo de tratamento e recuperação da informação, bem como os conceitos e termos a ele associados. No entanto, este arcabouço parece possuir alguns problemas metodológicos, entre eles a construção de conceitos descritivos sem uma paralela preocupação com a elaboração de conceitos metodológicos correspondentes e a perspectiva eclética adotada em sua construção. Tais constatações parecem indicar que a biblioteconomia e documentação possuem uma frágil ruptura com o senso comum. Logo, se área pretende participar do campo científico, como indica o termo ciência da informação, deve assumir uma postura diferenciada diante das metodologias científicas e mais especificamente da construção de conceitos.

\section{Palavras-chave}

Biblioteconomia; Documentação; Ciência da informação; Construção de conceitos;

Ruptura epistemológica.
A constituição e desenvolvimento de uma ciência exige dos seus pesquisadores e profissionais observação, reflexão e crítica das metodologias e padrões científicos vigentes, sem o que a produção científica do campo (bem como as propostas teóricas e práticas nela contidas) poderá redundar em discursos de grande proximidade com o senso comum.

Assim, o objetivo do presente artigo é refletir sobre a construção conceitual no campo da ciência da informação. Esta reflexão tem duas justificativas básicas: a) a formulação dos conceitos possibilita a ruptura epistemológica com o senso comum, ou seja, é um dos caminhos possíveis para a construção de uma ciência; b) os conceitos são os materiais empregados na elaboração de modelos científicos que, por sua vez, permitem a observação, descrição e interpretação dos objetos teóricos e empíricos de um campo do conhecimento, assim como os fenômenos presentes, passados e futuros a eles relacionados.

As duas justificativas mencionadas têm por base os trabalhos de Bourdieu e de Rubem Alves. Ao discutir o conceito de ruptura epistemológica (construção dos conceitos científicos sem a "interferência" das pré-noções presentes na linguagem comum), escreve Bourdieu:

“(...) en la medida en que el linguagen común y ciertos usos especializados de las palabras comunes constituyen el principal vehiculo de las representaciones comunes de la sociedad, una crítica lógica y lexicológica del lenguage común surge como el paso previo más indispensable para la elaboración controlada de las nociones científicas."'

* Artigo baseado em capítulo da dissertação de mestrado A ciência da informação: estudo epistemológico, defendida, em junho de 1997, na Escola de Comunicações e Artes da Universidade de São Paulo.
Já Rubem Alves esclarece:

"Um modelo é um artefato construído pelo cientista.

Quando falamos em artefatos, pensamos em coisas fabricadas com o auxílio de materiais sólidos, como relógios, máquinas de moer carne, cortadores de unha, satélites artificiais. Todos são artefatos produzidos pela arte dos homens.(...)

Para se construir um modelo, fazemos uso não de materiais sólidos, mas de conceitos."

Guiando-nos pelos autores citados anteriormente, podemos afirmar que, para a ciência da informação atingir um padrão de cientificidade, seus pesquisadores e profissionais precisam estar atentos à formulação de conceitos. ${ }^{3}$

Sabemos que a ciência da informação possui várias relações com a biblioteconomia e com a documentação. Isto porque grande parte dos cursos, dos institutos e periódicos que tinham em seus nomes os termos biblioteconomia e documentação, em certo momento histórico, substitui esses termos pelo termo ciência da informação. Um segundo aspecto que nos leva à constatação de tais relações é o fato de a literatura especializada, quer seja nacional ou internacional, muitas vezes, associar ou estabelecer equivalência entre os termos biblioteconomia, documentação e ciência da informação, sem necessariamente esclarecer os conceitos a que se referem e suas especificidades.

Na reflexão presente, consideramos que o termo ciência da informação surgiu para denominar e representar uma tentativa teórica e prática de superação da biblioteconomia e da documentação. Dessa maneira, o nosso ponto de partida será discutir a base conceitual da 
biblioteconomia e documentação e, paralelamente, observar se o fato de este campo do conhecimento ter se submetido a uma nova terminologia, ou seja, ter passado a empregar o termo ciência da informação, implicou um comportamento diferenciado diante das metodologias e padrões científicos.

Comumente, afirma-se que a biblioteconomia e a documentação têm por objetivos básicos a análise, organização e disseminação da informação. Ratificando tal afirmação, algumas obras de referência associam as metodologias vigentes na área de biblioteconomia e documentação, bem como as funções exercidas por seus profissionais, ao fluxo do tratamento e recuperação da informação.

Para melhor compreensão do fluxo apresentado na figura 1 , serão expostos a seguir os conceitos dos termos que o compõem.

Entende-se por universo de documentos o conjunto de todos os suportes físicos existentes (livros, filmes, discos, fitas $\mathrm{K}-7$, vídeos, CDs, periódicos, anais de congressos, atas, relatórios, cartazes, manuscritos, fotografias, teses, histórias em quadrinhos, mapas, plantas...) nos quais estão as informações produzidas pelo conhecimento humano.

Documento selecionado é aquele de interesse para um determinado sistema de informação (bibliotecas, centros de documentação, arquivos, museus, centros culturais, gibitecas, fonotecas ou videotecas), tendo em vista seus usuários e os recursos disponíveis na instituição na qual está inserido.

A análise referida aqui corresponde ao procedimento de verificação da informação contida no documento. Reside, basicamente, segundo Kobashi, na identificação da superestrutura textual (tema, problema, hipótese, metodologia, resultado e conclusão - por exemplo) ${ }^{4}$

A síntese é a construção realizada pelo documentalista de um enunciado relativo à informação contida no documento e que será submetido à representação temática.

Quanto à representação temática, podem ser citados dois tipos.

FIGURA 1

Fluxo do tratamento e da recuperação da informação

Universo de documentos

$\downarrow$

Documento selecionado

$\downarrow$

Análise

$\downarrow$

Síntese

$\downarrow$

Representação temática e representação descritiva

$\downarrow$

Índices/bases de dados

$\uparrow$

Representação da pergunta

$\uparrow$

Análise da pergunta

Solicitação do usuário

$\uparrow$

Usuário do sistema

No primeiro:

"A representação é realizada através do uso de um código comutador, ou seja, uma linguagem documentária - LD, que tem como função a normalização das unidades significantes ou conceituais presentes no texto original, a partir de elementos que constituem, de alguma forma, uma condensação de áreas de assunto. A condensação, nesse caso, é expressa pelos elementos do código de comutação, sendo, portanto, exterior ao texto submetido à conversão. Dessa forma, a representação obtida não representa necessariamente uma relação de contigüidade e semelhança com o texto original e envolve, pelo menos, dois sistemas semióticos distintos: aquele presente no texto original e aquele estabelecido pelo instrumento comutador ou LD." 5

Este primeiro tipo de representação temática pode ser explicitado pelo exemplo que se segue.

Se identificarmos na leitura (análise) do texto que suas informações referem-se a câncer e a alguma droga para sua cura, "traduziremos" este assunto para uma linguagem documentária que, dependendo de sua concepção e especificidade, vai nos permitir o uso dos termos câncer e droga, ou, por exemplo, neoplasia e quimioterapia, ou ainda doença e remédio.
Dessa forma, as diferentes linguagens documentárias possibilitam maior ou menor grau de abstração e generalização da representação temática a ser realizada, como afirma a norma ISO2788:

"If a popular and a scientific name to refer to the same concept, the form most likely to be tought by the users of the index should be chosen. For example, 'Penguins' might be chosen as the prefered in a general index, but the scientific equivalent, 'Sphenisciformes', may be prefered in a zoological index. Reciprocal references should be made in theses cases."6

No segundo tipo:

"A representação é construída através de um processo de condensação intensiva do texto original. Essa representação gera uma série de produtos documentários (vários tipos de resumo) que representam, geralmente, uma relação de contigüidade e semelhança com o texto que lhes deu origem, a operação, nesse caso, vale-se, em princípio, dos mesmos elementos do sistema semiótico utilizado para a elaboração do texto original."7 
Quanto à representação descritiva, podemos dizer que ela contempla os dados ligados à produção editorial dos documentos, tais como o responsável pela obra, título da publicação, editor, ano de publicação, número de páginas. Um dos produtos deste tipo de representação vem a ser a referência bibliográfica.

Os Índices, automatizados ou não, contêm os dados necessários para os usuários do sistema informacional decidirem a quais documentos querem ter acesso. Esses dados dizem respeito à representação descritiva (responsável pela obra, data de publicação, editora, paginação, forma física...) e à representação temática (resumo ou termos descritores de uma linguagem documentária).

Idealmente, os dados presentes nos índices dos sistemas informacionais seguem normalizações e linguagens específicas. Dessa maneira, a representação da pergunta visa a padronizar, através da linguagem documentária, as questões formuladas pelo usuário para que informações compatíveis sejam recuperadas. Sem o procedimento de representação da pergunta, corre-se o risco de o usuário não obter a informação que deseja, mesmo que o sistema tenha tal informação.

Dessa maneira, se, por exemplo, o usuário solicita informações sobre câncer, teremos de verificar se a linguagem documentária do sistema emprega o termo câncer ou o termo neoplasia para especificar as informações a respeito da enfermidade.

O objetivo da etapa de análise da pergunta é identificar com precisão quais informações o usuário quer. Ele pode solicitar, genericamente, informações sobre diabetes, mas de fato necessitar de informações sobre seres humanos do sexo masculino, não-fumantes, entre 30 e 40 anos, diabéticos, que não recebem tratamento quimioterápico ou dietoterápico.

Solicitação do usuário é o ato pelo qual o usuário procura, dentro de um sistema de informação, a informação que satisfaça suas necessidades informacionais.
O usuário do sistema é o público que utiliza o sistema de informação.

Como pode ser observado, a biblioteconomia e a documentação, para concretizar o objetivo de analisar, organizar e disseminar a informação, utilizam um conjunto de termos e conceitos que se referem a operações concretas.

Embora os conceitos dos termos explicitados até o momento sejam empregados constantemente, observamos que algumas problematizações podem ser levantadas sobre os mesmos, bem como outros termos e conceitos parecem ser necessários à biblioteconomia e documentação. Apresentaremos algumas problematizações, termos e conceitos nos parágrafos seguintes.

\section{O termo documento}

Na figura 1, embora o fluxo seja denominado fluxo do tratamento e da recuperação da informação, observa-se que o ponto de partida apresentado não são informações, mas sim documentos. Ou seja, parece que a biblioteconomia e a documentação tendem a tratar os termos informações e documentos como se fossem equivalentes.

Além disso, o termo documento é empregado, na área de biblioteconomia e documentação, ora como equivalente ao termo suporte de dados ("objeto material sobre o qual ou no qual uma variável física específica - perfurações em série, sinais magnéticos, signos visuais, auditivos etc.- pode representar da-

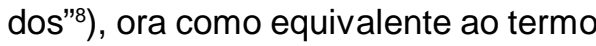
meio de comunicação ("canal ou cadeia que liga a fonte ao receptor") e ora associado ao termo mensagem ("sinônimo de 'conteúdo', ou seja, aquilo que é dito em um texto, em um discurso"10) -, sem que haja explicitação à qual das conceituações apresentadas o termo documento está se referindo.

\section{0 termo linguagem}

No campo da biblioteconomia e documentação, pode-se distinguir pelo menos duas correntes teóricas cujas preocupações estão voltadas ao estudo da linguagem: a corrente teórica que pesquisa a viabilidade da recuperação de informações via linguagem natural e a corrente que trabalha no desenvolvimento das linguagens do- cumentárias. Também, pode-se perceber que essas correntes têm procurado seus subsídios na estatística, na ciência cognitiva, na lógica, na lingüística, na matemática, na ciência da terminologia, entre outras.

Tentando não tomar partido, a observação que fazemos é a de que as duas correntes, ao selecionar seus objetivos empíricos para a análise, acabam se detendo prioritariamente em textos técnico-científicos escritos. Uma das justificativas para este procedimento é proposta por Lara da seguinte forma:

“(...) nos textos técnico-científicos, as relações de significação pressupõem uma univocidade de significação, ou seja, um corpo conceitual proposto por consenso (ou discussão, quando da quebra de paradigmas), conhecimento, produção, rearranjos, seguindo correntes institucionais de pensamento e posição: ou seja, um referente e um contexto. Desse modo, pretende-se tomar o signo monossêmico como base para a transmissão da informação documentária."11

Todavia, a presença do signo monossêmico não é característica de todos os textos técnico-científicos. Gomes afirma que:

"As disciplinas normativas como o Direito, por exemplo, têm, por força de natureza, grande preocupação com o estabelecimento claro de conceitos e termos em seus documentos legais, embora, por questões de política, alguns termos fiquem propositalmente obscuros, dando margem a sua utilização conforme predomine esta ou aquela tendência política (...) Nas ciências sociais (...), além de, numa mesma comunidade de especialistas coexistirem pensadores/cientistas adotando diferentes paradigmas, são usadas palavras e expressões tomadas da linguagem natural, de uso comum ou emprestadas de outras áreas, sendo-Ihes atribuído, contudo, novo conteúdo conceitual, sem que este fato esteja claro para os ouvintes, leitores fora de seu estreito círculo e, em alguns casos, até mesmo dentro de tal círculo."12 
Ao verificarmos as pesquisas sobre linguagem desenvolvidas na área e as afirmações de Lara e Gomes, chegamos à conclusão de que a biblioteconomia e a documentação, ao desenvolverem metodologias para o tratamento apenas dos textos técnico-científicos e ao objetivarem a construção do signo monossêmico como base para a transmissão da informação, têm tratado apenas uma parte das informações produzidas pela humanidade, uma vez que os textos literários e visuais, por exemplo, não têm sido objetos de estudo. Observa-se igualmente que a biblioteconomia e a documentação não operam com o conceito geral de linguagem que a relaciona com "qualquer sistema de signos (não só vocais ou escritos, como também visuais, fisionômicos, sonoros, de gestos etc.) capaz de servir à comunicação entre os indivíduos."13

\section{O termo comunicação}

O fluxo apresentado na figura 1 parece propor uma mediação entre o produtor de informação e o usuário da informação. Não considera que está ocorrendo uma sobreposição entre o ser humano produtor de informação e o ser humano usuário de informação. No momento, final do século XX, as informações estão sendo produzidas, reelaboradas e disseminadas ao mesmo tempo, sendo o ciclo de informação mais ágil ${ }^{14,15}$, fato que dificulta inclusive a identificação do autor responsável pela informação e a aplicação dos direitos autorais. Como mediar neste contexto?

\section{O termo administração}

A nosso ver, o fluxo apresentado na figura 1 também é uma proposta de linha de produção de produtos informacionais (ou melhor, de análise, síntese e representação de textos técnico-científicos). Não é discutido pela biblioteconomia e documentação se tal fluxo serve para qualquer sistema de informação ou em quais sistemas ele pode ser ou não ser aplicado. Não se discute se o fluxo é válido em sistemas em que os usuários são adolescentes, idosos, possuem ou não escolaridade. Não se discute se os produtos elaborados pela biblioteconomia e documentação são de interesse para os usuários. Enfim, não se discute a tipologia dos sistemas de informação e as especificidades de seus usuários.
Dessa forma, a biblioteconomia e documentação, que não chegaram sequer a atingir os mercados maciços, não dispõem também de métodos para fornecer produtos adaptados a cada tipo de público (donas de casa, crianças, adolescentes etc.), apesar de termos, na economia atual, uma tendência do crescimento de produtos adaptados ao cliente $^{16}$

\section{O termo serviço e o termo usuário de informação}

A observação do fluxo apresentado na figura 1 evidencia que o usuário do sistema de informação não é visto, de fato, como prioridade, pois o ponto de partida está voltado para o documento, sem que haja, ao longo do fluxo, menção aos usuários do sistema. Dessa maneira, o pensamento habitualmente empregado pelos profissionais da área, cujo objetivo-fim de um sistema de informação é o usuário, pode ser questionado, pois fica difícil atingir o objetivo-fim sem que o usuário seja considerado desde o início do processo de tratamento e recuperação da informação.

A dúvida que surge é a seguinte: se, de fato, o usuário fosse a prioridade (ou seja, se, antes de se criarem serviços ou produtos para os sistemas de informação, houvesse não só a preocupação, mas um estudo sobre quem é esse usuário, o que ele entende por informação, que fontes de informação ele prioriza e utiliza, como ele habitualmente obtém as informações de que necessita, como ele se comunica, que tipo de linguagem emprega etc.), os sistemas de informação continuariam elaborando os mesmos serviços e produtos atuais?

Atualmente, o usuário, por não ser visto como prioridade, precisa se adequar ao que the é oferecido. Os serviços oferecidos pela biblioteconomia e documentação funcionam como matrizes que moldam as formas de seu consumo ${ }^{\star 17,18,19}$. Em outras palavras, quando o usuário fica satisfeito com as informações encontradas nos sistemas de informação, ele fica satisfeito dentro de uma expectativa que foi construída ao

\footnotetext{
* Segundo Anders, o homem aprende a necessitar daquilo que lhe oferecem. A oferta é um mandamento. A decisão é relativa. $\mathrm{O}$ produto fabrica o vício de seu consumo.
}

longo de sua relação com esse sistema. Assim, os produtos e serviços oferecidos pela biblioteconomia e documentação não são neutros. Eles moldam as necessidades dos usuários dos sistemas de informação.

Uma possibilidade para se reverter o quadro apontado seria não apenas colocar o usuário como prioridade, mas também, por exemplo, saber que tipo de informação o não-usuário do sistema de informação está procurando, que tipo de necessidade esse público possui. Com esse parâmetro, haveria uma avaliação menos tendenciosa sobre a contribuição efetiva da biblioteconomia e da documentação à sociedade - sendo que os objetos de pesquisa da área não residiriam nas atividades existentes no fluxo da figura 1, ou seja, os objetos de pesquisa não seriam de "mecanismo inibidor do pensar acadêmico."20

No entanto, comumente, para os profissionais da biblioteconomia e da documentação, o público não-usuário do sistema de informação é visto como pessoas que não sabem utilizar ou têm dificuldade em utilizar os recursos informacionais disponíveis nos sistemas de informação e que precisam, portanto, ser iniciadas às regras destes. Há, assim, uma dissimetria entre o usuário (público efetivo) e os não-usuários (público potencial).

Se existem públicos que têm dificuldade em utilizar com eficiência esses sistemas, talvez fosse o caso de mudar as metodologias empregadas nos sistemas de informação ao invés de se transferir o problema para o cliente.

Fizemos essas colocações porque as posições da biblioteconomia e da documentação são muito cômodas. Tendo como sustentação o fluxo da figura 1 , elas acabam atendendo a um pequeno segmento da população e virando as costas para outros segmentos. Além disso, a biblioteconomia e documentação parecem não perceber que as ciências humanas não podem trabalhar apenas com modelos estáticos, pois o objeto estudado pelas humanidades possuem características diferenciadas do objeto estudado pelas ciências exatas. As seguintes afirmações esclarecem este ponto: 
"Cientistas das chamadas ciências exatas freqüentemente se riem dos seus companheiros das ciências humanas e chegam mesmo a perguntar se tais ciências são mesmo ciências.

A questão, entretanto, está mal colocada.

O rigor das ciências da natureza não se deve, em absoluto, a que elas sejam mais rigorosas e seus métodos mais precisos.

Acontece que o bicho com que elas lidam é muito doméstico, manso, destituído de imaginação, faz sempre as mesmas coisas, numa rotina enlouquecedora, freqüenta os mesmos lugares. Tanto assim que é possível prever onde estarão Terra, Sol e Lua daqui a 100 mil anos.

Se eu lhe desse duas tarefas:

1) desenhe os movimentos de uma árvore;

2) desenhe os movimentos de uma bailarina dançando balé.

Qual dos dois desenhos seria mais preciso?

\section{Evidentemente o da árvore.}

Por quê? Por que você possui métodos mais rigorosos para lidar com a árvore? Não. Porque a árvore não sai do lugar, não muda de idéia." ${ }^{21}$

Do que foi dito, percebe-se que o objeto das ciências humanas (o ser humano) sofre alterações com o passar do tempo. Entendendo que o usuário da informação é um ser humano, a biblioteconomia e documentação teriam seus objetivos centrados não apenas na otimização dos serviços que prestam à sociedade, estariam atentas às mudanças, às novas exigências informacionais e proporiam serviços e conceitos compatíveis com os diferentes momentos históricos.

\section{O termo informática}

A função da informática não está evidente para quem observa o fluxo da figura 1. Porém, considerando-se que este fluxo já está sendo utilizado pela biblioteconomia e documentação há alguns anos e que, após o advento da informática, o fluxo continua estático, isto é, sem atualização, pensamos que a informática é vista nessa área como um instrumento de agilizar/otimizar processos.

O conceito de informática precisa também ser redimensionado. Os profissionais e pesquisadores da biblioteconomia e documentação não podem ver na informática apenas um instrumento que será utilizado dentro do fluxo documento selecionado-análise-síntese-representação-índices.... É preciso questionar esse fluxo e ver tanto as metodologias vigentes na área, quanto o "uso da informática" de um ponto de vista mais amplo.

Como afirma Lynch, há uma diferença entre modernização e transformação de processos $^{22}$. Se no passado a informática foi vista como um instrumento para tornar mais eficientes algumas atividades (ou seja, para modernização/otimização de processos), hoje a informática está colocando em xeque essas atividades (ou seja, está transformando os processos).

\section{As áreas de pesquisa}

Além das problematizações levantadas, é preciso esclarecer que muitos dos conceitos e termos discutidos anteriormente têm orientado: a) as atividades profissionais do bibliotecário e do documentalista; b) os currículos de graduação e pós-graduação em biblioteconomia e documentação; c) o desenvolvimento da produção "científica" neste campo do conhecimento. Atualmente, por exemplo:

a) universo de documentos e documentos selecionados relacionam-se com as áreas de pesquisa, ensino e atuação profissional denominadas fontes de informação, desenvolvimento de coleções, seleção; b) análise, síntese e representação temática relacionam-se com as áreas de pesquisa, ensino e atuação profissional denominadas análise documentária, repesentação temática, representação de conteúdo, classificação;

c) representação descritiva relaciona-se com as áreas de pesquisa, ensino e atuação profissional denominada representação descritiva ou catalogação;

d) representação da pergunta relacionase com a área de pesquisa, ensino e atuação profissional denominada serviços de referência;

e) solicitação do usuário e usuários do sistema relacionam-se com as áreas de pesquisa, ensino e atuação profissional denominadas ação cultural, serviços de referência, usos e usuários de informação;

f) por fim, teríamos as áreas de pesquisa, ensino e atuação profissional denominadas administração de sistemas de informação, administração de bibliotecas e também informática documentária, cujos objetos residem no fluxo como um todo.

Pelo exposto, a biblioteconomia e documentação parecem possuir como modelo de sustentação o fluxo do tratamento e da recuperação da informação. Logo, a construção e a análise dos sistemas de informação realizadas pelo estudante, profissional e pesquisador da biblioteconomia e documentação, em diferentes contextos sócio-políticos-culturais e históricos em que ocorrem, parecem seguir uma única estrutura (o fluxo do tratamento e da recuperação da informação), impossibilitando o surgimento de outras novas estruturas.

\section{Problemas conceituais na biblioteconomia e documentação}

Ducrot define conceitos metodológicos e conceitos descritivos. Para o autor, enquanto aqueles englobam conceitos mais gerais, estes englobam mais particulares. Parafraseando Ducrot, poderíamos dizer que os conceitos metodológicos relacionam-se com a teoria, enquanto os conceitos descritivos são mais voltados à operacionalidade da teoria, devendo haver para o conceito descritivo pelo menos um conceito metodológico e vice-versa. 
No percurso histórico da biblioteconomia e da documentação, sempre conceitos e denominações provenientes de outras ciências ou disciplinas foram importados e/ou adaptados com o intuito de se obterem soluções para problemas práticos. Nesse sentido, importaram-se conceitos e denominações de algumas teorias da administração, da lingüística, da lógica, da comunicação e de outras áreas. Porém, visando-se a um uso imediato desses conceitos e denominações, não houve compreensão/problematização dos conceitos metodológicos e conceitos descritivos e um questionamento sobre as implicações do uso de conceitos e denominações provenientes de diferentes áreas do conhecimento.

A título de exemplo, podemos mencionar que, da administração, foram importados vários conceitos da teoria clássica e, da lingüística, foram importados conceitos da teoria dos campos conceituais. Tais importações levaram a biblioteconomia e a documentação a:

a) elaboração de conceitos descritivos compatíveis com os conceitos metodológicos de origem, mas que, com o passar do tempo, foram se tornando desatualizados em relação ao estado-da-arte tanto da administração, quanto da lingüística;

b) elaboração de conceitos descritivos incompatíveis com os conceitos metodológicos de origem;

c) em decorrência dos itens a e b, nos momentos em que a biblioteconomia e documentação tentaram atualizar os conceitos descritivos que utilizam, não obtiveram êxito devido à ausência de conceitos metodológicos internos à área.

As observações realizadas indicam que a área se voltou para questões circunstanciais e procurou, na importação de conceitos e denominações provenientes de outras ciências, uma justificativa "científica" para a atividade prática, adotando, muitas vezes, uma postura eclética.

O conceito de ecletismo por nós adotado segue a definição estabelecida por Oliveira Filho. Segundo ele:
"Ecletismo é o uso de conceitos fora dos seus respectivos esquemas conceituais e sistemas teóricos, alterando os seus significados. A ocorrência do termo, sem definição que reduzisse ou eliminasse a sua ambigüidade, não permitiria saber a qual de vários conceitos possíveis está associado. Inadvertidamente, muitas vezes, utiliza-se o sinal que expressa o conceito, mas não o próprio conceito. O discurso torna-se vazio ou obscuro sem que o cientista social perceba que a sua linguagem pode dificultar a comunicação. Se tal ocorrência é grave em nível da teoria, será gravíssima em nível metateórico ou meta-sociológico. Neste caso, os conceitos metodológicos desprovidos de suas características limitar-se-ão a nomeações e classificações rituais de postura sem qualquer influência nas estratégias de investigação, o que é comum em textos produzidos por autores desprovidos de treinamento metateórico. Termos vazios de significado não podem funcionar como instrumentos de reconstrução teórica ou metodológica."

As observações realizadas também indicam que, ao importar conceitos e denominações oriundos de outras áreas, a área de biblioteconomia e documentação não estabeleceu uma ruptura epistemológica necessária para a constituição de um arcabouço conceitual próprio.

A biblioteconomia e a documentação não propõem conceitos. Estando voltadas para o objetivo de analisar, organizar e disseminar a informação, importam denominações e conceitos de outras áreas sem estabelecer um debate ou uma problematização sobre a que conceito se refere a denominação importada ou a qual denominação se refere o conceito importado. Com isso, nesta área, a ruptura com o senso comum parece ser muito frágil, ou quase inexistente.

Tendo elaborado este esboço sobre os conceitos da biblioteconomia e documentação, resta uma questão: a ciência da informação possui as mesmas características da biblioteconomia e documentação?
Ao formularmos esta questão, não queremos afirmar que a ciência da informação existe; ou que é possível determinar onde começam ou terminam essas áreas do conhecimento; ou que a ciência da informação é algo diferente da biblioteconomia e documentação. No entanto, ressaltamos que, se os profissionais, pesquisadores e estudantes da ciência da informação desejam avançar na constituição teórica deste campo do conhecimento, precisam estar atentos para a forma como a biblioteconomia e documentação têm formulado e empregado termos e conceitos. Se a área achava que a modificação de sua autodenominação para ciência da informação a tornaria ciência e que seria reconhecida no âmbito acadêmico enquanto tal, equivocou-se. É preciso discutir sua base conceitural e, principalmente, como está trabalhando e empregando as metodologias científicas. 
this article, the basic premisse is that conceptual construction interfere on epistemoly and on scientific models development that helps analyse, describe and interpret the theorical and empirical objects of a knowledge area. A conceptual framework draft of librarianship and documentation was stablished and, trough it, many conceptual problems were detected in this area like absence of methological concepts construction and eclecticism. Afteward, the conceptual construction in Information Science is questioned.

\section{Keywords}

Librarianship; Documentation; Information Science; Concepts construction; Epistemology.

\section{REFERÊNCIAS BIBLIOGRÁFICAS}

1. BOURDIEU, Pierre et al. El ofício de sociólogo. México: Siglo XXI, 1986. p.28

2. ALVES, Rubem. Filosofia da ciência: introdução ao jogo e suas regras. 17ed. São Paulo : Brasiliense, 1993. p.59

3. GALVÃO, M.C.B. Os conceitos dos termos biblioteconomia, documentação e ciência da informação. Revista Brasileira de Biblioteconomia, v.26, n.1/2, p.100-114, jan./jun. 1993.

4. KOBASHI, Nair Yumiko. A elaboração de in formações documentárias: em busca de uma metodologia. São Paulo : CBD/ECA/ USP, 1994. (tese de doutorado)

5. LARA, M.L.G. de. A representação documentária: em jogo a significação. São Paulo: CBD/ECA/USP, 1993. p.4-5 (Dissertação de mestrado)

6. ISO. Establishment and development of monolingual thesauri. 10 2788-1986. p.8

7. LARA, M.L.G. de. A representação documentária: em jogo a significação. São Paulo: CBD/ECA/USP, 1993. p.4 (Dissertação de mestrado)

8. RABACA, C.A., BARBOSA, G. Dicionário de comunicação. Rio de Janeiro : Codecri, 1978. p.442

9. RABACA, C.A., BARBOSA, G. Dicionário de comunicação. Rio de Janeiro : Codecri, 1978. p.305

10. KATZ, C.S. et al. Dicionário básico de comunicação. 2.ed. Rio de Janeiro : Paz e Terra, 1975. p.290

11. LARA, M.L.G. de. A representação documentária: em jogo a significação. São Paulo: CBD/ECA/USP, 1993. p.44 (Dissertação de mestrado)

12. GOMES, Hagar Espanha. Estudo científico da terminologia: tendências. TradTerm, v.1, p.97-106,1994. p.104

13. RABACA, C.A., BARBOSA, G. Dicionário de comunicação. Rio de Janeiro : Codecri, 1978. p.281

14. IMATERIALIDADES. Atrator Estranho, v.3, n.11, maio, 1995.

18. ANDERS et al. Die Zerstörung einer Zukunft. Rowohlt: Reinbek bei Hamburg, 1979.

19. ANDERS. Die Antiquiertheit des Menschen. (2) Ueber die Zerstoerung des Lebens im Zeitalter der dritten industriellen Revolution, 4.ed. Munique: Beck, 1995.

20. BARRETO, Aldo de Albuquerque. Pensando a pós-graduação em informação no Brasil. In: ENCONTRO NACIONAL DOS CURSOS DE PÓS-GRADUAÇÃO EM CIÊNCIA DA INFORMAĈ̃O E BIBLIOTECONOMIA, 12, São Paulo, 11 a 13 de março de 1992. Anais...São Paulo: ANCIB/CNPq/ ECA-USP, 1993. p.24

21. ALVES, Rubem. Filosofia da ciência: introdução ao jogo e suas regras. 17ed. São Paulo : Brasiliense, 1993. p.97-98

22. LYNCH, Clifford A. The transformations of scholarly communications and the role of the library in the age of networded information. In: SCHOLARLY COMMUNICATION AND NETWORKING TECHNOLOGIES. Plenary Session 1. June 19, 1992. p.8

23. DUCROT, Oswald \& TODOROV, Tzvetan Dicionário das ciências da linguagem. Lisboa: Dom Quixote, 1974. p.14

24. OLIVEIRA FILHO, José Jeremias. Patologias e regras metodológicas. Estudos Avançados, v.9, n.23, p.263-268, jan/abr. 1995. p.263

Artigo aceito para publicação em 21-10-97.

15. STIK, Gary. The speed of write. In: Encuentros Nacionales Gestión de Información. Santiago de Chile: CEPAL, Clades, 1995.

16. MARTIN, Willian. La industria de la información. In: Encuentros Nacionales Gestión de Información. Santiago de Chile : CEPAL; CLADES, 1995

17. ANDERS, G. Die Antiquiertheit des Menschen. (1) Ueber die Seele im Zeitalter der industriellen Revolution, 7.ed. Munique; Beck, 1994.

\section{Maria Cristiane Barbosa Galvão}

Bacharel em biblioteconomia e documentação e mestre em ciência da informação pela Escola de Comunicações e Artes da Universidade de São Paulo. Docente do Departamento de Ciência da Informação da Universidade Federal de São Carlos.

E-mail: mgalvao@guarany.cpd.unb.br 